\title{
ASSESSMENT OF CLIMATE CHANGE IMPACTS ON THE HYDROLOGIC RISK BY QUANTITATIVE ALTERATION IN THE CATALAN INTERNAL BASINS
}

\author{
LAURA RAMOS SOLER ${ }^{1}$, JAVIER PAREDES ARQUIOLA ${ }^{1}$, \\ JOAQUÍN ANDREU ÁLVAREZ ${ }^{1} \&$ ANTONI MUNNÉ TORRAS ${ }^{2}$ \\ ${ }^{1}$ Universitat Politècnica de València, Spain \\ ${ }^{2}$ Agencia Catalana del Agua, Spain
}

\begin{abstract}
The Catalan Internal Basins has a peculiarity in respect of other Mediterranean basins; its total urban demand exceeds the agriculture extractions, so the returns of the wastewater treatment plants have special relevance in the total water balance. Usually, the main quantitative alterations of the hydraulic regime of the rivers are the regulation of reservoirs and the demands. The main objective of this study is to include and evaluate the quantitative pressure of urban discharges on the analysed system, in order to estimate the altered regime risk of water bodies and analyse their evolution in future scenarios of Climate Change. The tool used to achieve these goals is the Rapid Response Environmental Status $\left(\mathrm{R}^{2} \mathrm{EA}\right)$ model. Firstly, from results, the percentage of the volume dumped over the total inflows of each of the bodies is calculated and the simulated period is evaluated. Secondly, the percentage of water extraction is calculated from discharges located upstream of the intake for each of the urban demands included in the model. These indices are calculated for three Climate Change scenarios. The calculated indices analysed show that the water regime alteration by discharges mainly affects temporal water bodies. In addition, a significant risk increase during summer months is identified. Finally, we propose that the water managers should use this approach in order to characterize the vulnerability level by quantitative alteration of aquatic ecosystems.
\end{abstract}

Keywords: water model, large scale, $R^{2} E A$, climate change, environmental risk.

\section{INTRODUCTION}

The direct and indirect consumption of natural resources is often accompanied by a degradation of the affected ecosystems. The main reasons are overexploitation and pollution [1]. Access to water resources is fundamental for the development of most human activities, as well as being essential to ensure a good level of quality of life for the populations [2].

Although it is a renewable resource due to the water cycle, in some regions the renewal capacity is lower than the rates of extraction or the pollution level, which is a challenge for the organizations responsible for the good condition of inland aquatic ecosystems [3], [4].

Increasing pressures on water resources increases the complexity of managing natural systems, especially in arid or semi-arid areas characterized by marked episodes of drought. The vulnerability of these zones creates the need to apply specific management techniques and strategies that promote the sustainable use of water [5], [6].

This situation has fostered the development of numerous indices that quantitatively reflect the use of this resource in a territory [7], [8]. Some examples are the Water Stress Index, Water Exploitation Index, Water Allocation or Exploitable Water Resources, among others.

In the present study, a specific index has been developed to quantitatively evaluate the pressure exerted by discharges from large-scale wastewater treatment plants (WWTP). For the calculation of this analysis, it will include a general approach to the state of the system, as well as a more detailed assessment of each of the surface water bodies that make up the 
fluvial network of the case study. In addition, changes in the vulnerability of ecosystems to this index during droughts and in future Climate Change scenarios will be analysed.

\section{STUDY CASE}

The study was carried out within the framework of the Catalan Internal Basins, a Spanish hydrographic demarcation located in the Northwest of the Iberian Peninsula (Fig. 1). The territorial scope of CIC includes the basins of the rivers Muga, Fluvià, Ter, Daró, Tordera, Besòs, Llobregat, Foix, Gaià, Francolí and Riudecanyes, and the coastal streams between the border with France and the outlet of the river Sénia. The set of internal basins is organised into 28 hydrological units, which are subdivided into 261 surface water bodies [9].

One of the peculiarities of this system is the importance of urban demand in relation to other consultative uses of water such as agriculture or industry. In total, 55\% of the extractions are destined to urban supply. This characteristic has motivated the decision to use the CIC as a pilot basin for the application of this analysis. It is assumed that urban returns from WWTP discharges will have special relevance in the total water balance of the system.

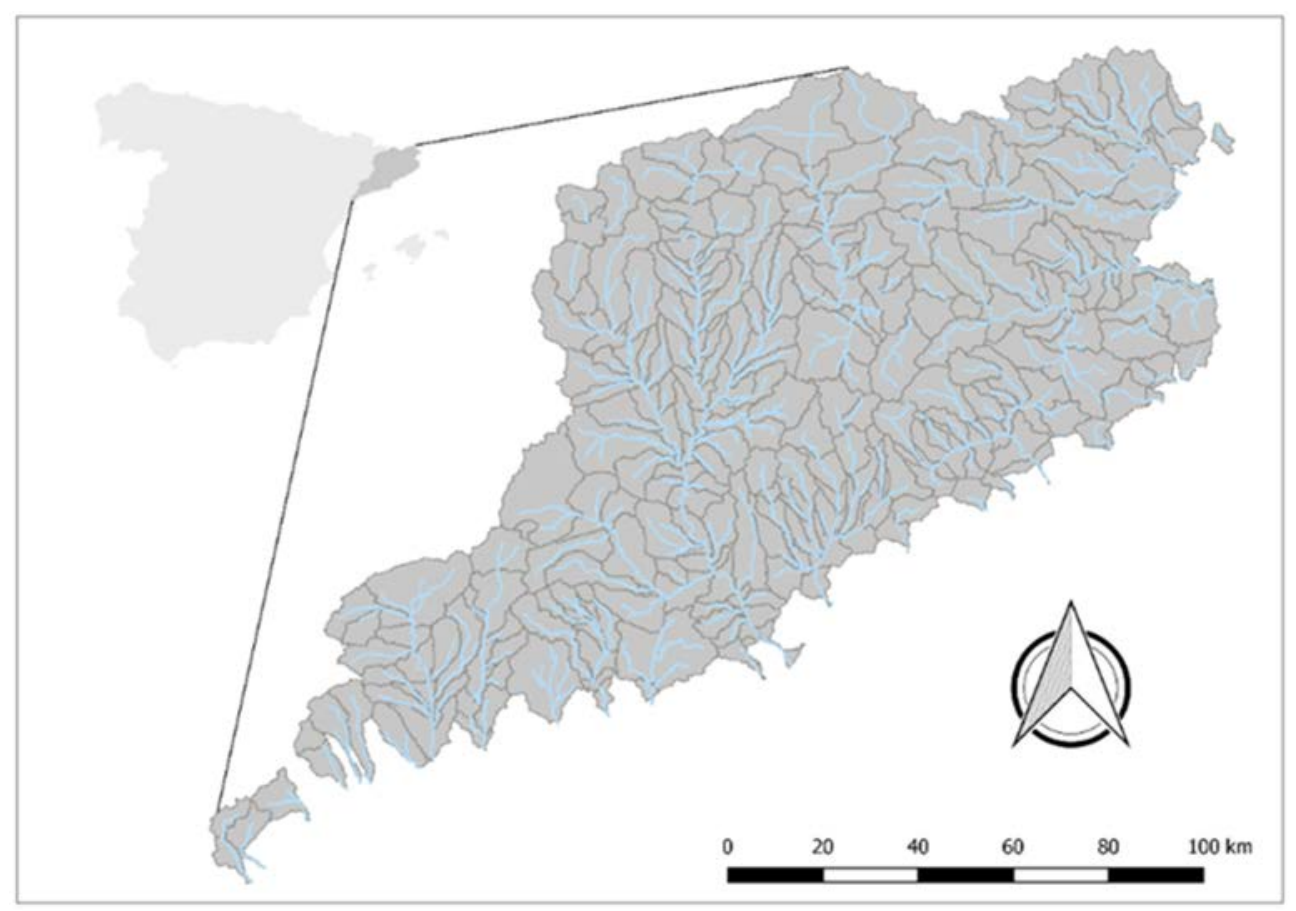

Figure 1: Location of Catalan Internal Basins and 261 sub-watersheds.

\section{DATA AND METHODOLOGY}

\subsection{Data}

Part of the data used for the development of this work has been provided by the Catalan Water Agency (ACA), the governmental body responsible for the management of the CIC. Among the information provided, they stand out: 
1. Inter-basin inflows for the period Oct/1980-Sep/2008, calculated using the Sacramento Soil Moisture Accounting (SSMA) model.

2. Database of registers of authorised dumping dossiers located in the study area.

3. Location of the most relevant water extraction points of the system for urban and agricultural supply.

4. Records of outflow from reservoirs located within the demarcation.

5. Database with a series of flows observed by the ACA's network of gauges.

In addition, information was downloaded from the European project SWICCA on the possible impacts to which the study area can be subjected to different scenarios of Climate Change. Of all the parameters offered by the SWICCA platform, the monthly percentage change has been used at the level of inflows by sub-basins. Table 1 shows the regional climate models for which the results have been used for calculating the average ratio change of the three Climate Change scenarios included in this work (Table 2).

Table 1: Regional climate models by emissions scenario.

\begin{tabular}{|c|c|c|}
\hline \multicolumn{3}{|c|}{ Model by emissions scenario } \\
\hline RPC2.6 & RPC4.5 & RPC8.5 \\
\hline $\begin{array}{ll}\text { - } & \text { CSC_REMO2009_M } \\
& \text { PI-ESMLR_rcp26 } \\
\text { - } & \text { SMHI_RCA44EC- } \\
& \text { EARTH_rcp26 }\end{array}$ & $\begin{array}{ll} & \text { KNMI_RACMO22E_ } \\
& \text { EC-EARTH_rcp45 } \\
\text { - } & \text { SMHI_RCA4_HadGE } \\
& \text { M2-ES_rcp45 } \\
\text { - } & \text { CSC_REMO2009_MP } \\
& \text { I-ESM-LR_rcp45 } \\
\text { - } & \text { IPSL_WRF33_CM5A_ } \\
& \text { rcp45 } \\
\text { - } & \text { SMHI_RCA4_EC- } \\
& \text { EARTH_rcp45 }\end{array}$ & $\begin{array}{ll}\text { - } & \text { KNMI_RACMO22E_E } \\
\text { C-EARTH_rcp85 } \\
\text { - } & \text { SMHI_RCA4_HadGE } \\
& \text { M2-ES_rcp85 } \\
\text { - } & \text { SMHI_RCA4_EC- } \\
& \text { EARTH_rcp85 } \\
\text { - } & \text { CSC_REMO2009_MPI } \\
& \text {-ESM-LR_rcp85 }\end{array}$ \\
\hline
\end{tabular}

Table 2: Percentage annual average change in inflows by zone.

\begin{tabular}{|l|c|c|c|}
\hline & \multicolumn{3}{|c|}{ Annual Mean (\% inflow change) } \\
\hline Catalonia Internal Basins areas & $\mathbf{2 0 2 0}$ & $\mathbf{2 0 5 0}$ & $\mathbf{2 0 8 0}$ \\
\hline Coast Basins & 5.82 & 4.82 & 7.00 \\
\hline Upper Llobregat & -3.73 & -5.36 & -8.82 \\
\hline Lower Llobregat & 0.25 & -0.95 & -2.53 \\
\hline Upper Ter & 0.45 & 0.09 & -2.55 \\
\hline Lower Ter & 6.53 & 4.43 & 3.32 \\
\hline
\end{tabular}

The study case has zoned according to the basin characteristics, in order to adjust, as far as possible, the impacts of the three Climate Change scenarios on the monthly inflows (Fig. 2). 


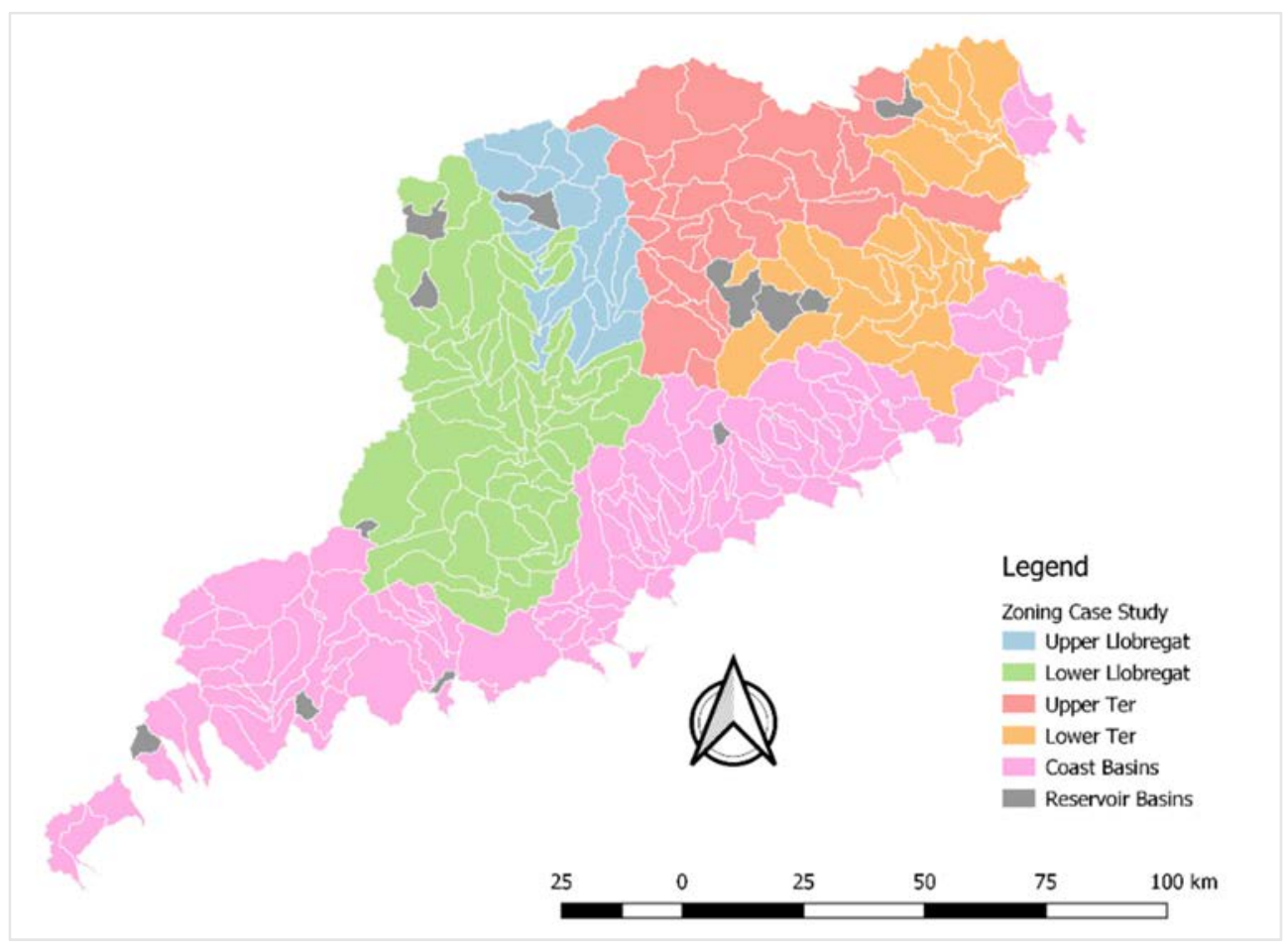

Figure 2: The study area zoning.

\subsection{Methodology}

In order to carry out the study, it was necessary to have a water balance of the entire system studied, which includes the main elements that directly affect the natural fluvial regime. The Rapid Response Tool of the Environmental State [ $\left.R^{2} E A\right]$ was used for its development. This model was developed by the water resources research group of the Universitat Politècnica de València and is aimed at quantitatively and qualitatively evaluating the effect of a large-scale strut and diffuse pollution. The present work has focused on evaluating the quantitative results offered by the model.

The $\mathrm{R}^{2} \mathrm{EA}$ tool requires the input data to be in a format and with specific units, so first a pre-treatment of data provided by the water authority was applied.

\subsubsection{Inflows}

The sub-basins used by the Sacramento method did not coincide with the classification of water bodies carried out by the ACA. Therefore, a first spatial extrapolation was made, through which the percentage of the Sacramento basin that coincided with the area of the ACA basins was assigned. The QGIS geospatial tool was used to carry out this step.

Then, the inflows from the Sacramento basins were distributed to the ACA basins. Finally, it was verified that the allocation had been correctly executed by checking whether the annual balance (1995-2008 period) of two head watersheds conformed to the data observed from the gauging stations downstream of them (Fig. 3). 

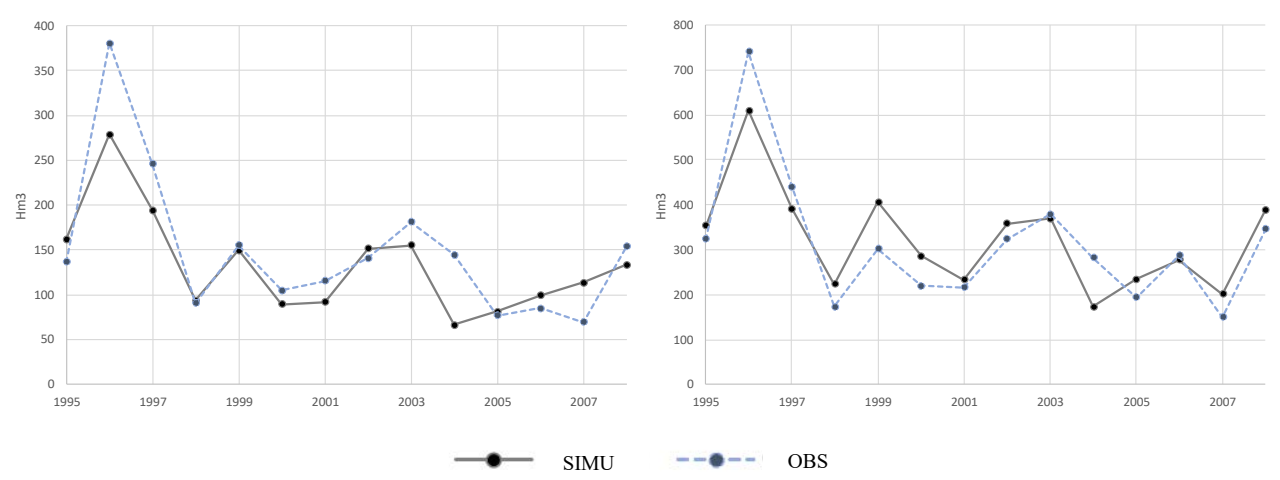

Figure 3: Check between simulated and observed flows.

\subsubsection{Discharges from WWTPs}

Once the inflows were adopted, the information in the discharge files was analysed. First, a geospatial analysis was performed using GIS to identify the masses affected by urban discharges. In this case, the geographic information system used was QGIS.

Next, the summation of the volume discharged per body of water was made, since in some cases the bodies of water are affected by more than one WWTP discharge. After this, a matrix was obtained where the total volume discharged by the water body and month are collected.

\subsubsection{Flow regulation and extraction}

In order to model the water balance in an altered regime and not in the natural one, the flows downstream of the main reservoirs were corrected using the outflow registers. In addition, the masses affected by the most important strut demands were located. In total, information was introduced on the regulation of five reservoirs (Susqueda, Darnius, Boadella, Foix, Sant Ponç and la Baells) and flow extractions were included for a total of $520.3 \mathrm{Hm}^{3}$.

\subsubsection{Simulations:}

Once the base model $\mathrm{R}^{2} \mathrm{EA}$ was built, the two first simulations carried out were executed by Climate Change scenario $(2020,2050,2080)$.

In the first one, the returns were not considered, so only the natural flows $\left(\mathrm{Q}_{\text {nat }}\right)$ are taken into account.

In the second, the water inputs to the WWTP discharge system $\left(\mathrm{Q}_{\text {disch }}\right)$ were included. Subsequently, the relationship between the total circulating flow $\left(\mathrm{Q}_{\text {total }}\right)$ and the circulating flow per discharge $\left(\mathrm{Q}_{\text {disch }}\right)$ was calculated, both in the current scenario and in the Climate Change scenarios.

$$
\begin{aligned}
& Q_{\text {total }}=Q_{\text {nat }}+Q_{\text {disch }} \\
& \% Q_{\text {disch }}=\frac{Q_{\text {total }}-Q_{\text {nat }}}{Q_{\text {total }}} .
\end{aligned}
$$

Finally, the global analysis of the state of the demarcation and the individual evaluation of each mass with respect to the calculated parameter were carried out. 


\section{RESULTS}

\subsection{Percentage of streamflows from urban discharges ( $\left.\% \mathrm{Q}_{\mathrm{disch}}\right)$.}

Fig. 4 shows the average relationship between the total flow and the flow from urban discharges of all the water bodies affected. We have identified 149 masses directly affected by discharges and 24 more that are indirectly affected. Fig. 4 shows a significant increase in the relationship between the natural flow and the flow from urban discharges during the summer months (June to October). In addition, the months with the highest and lowest discharge pressure risk are September and February, respectively. Finally, there are no significant differences between the global results obtained for the three Climate Change scenarios.

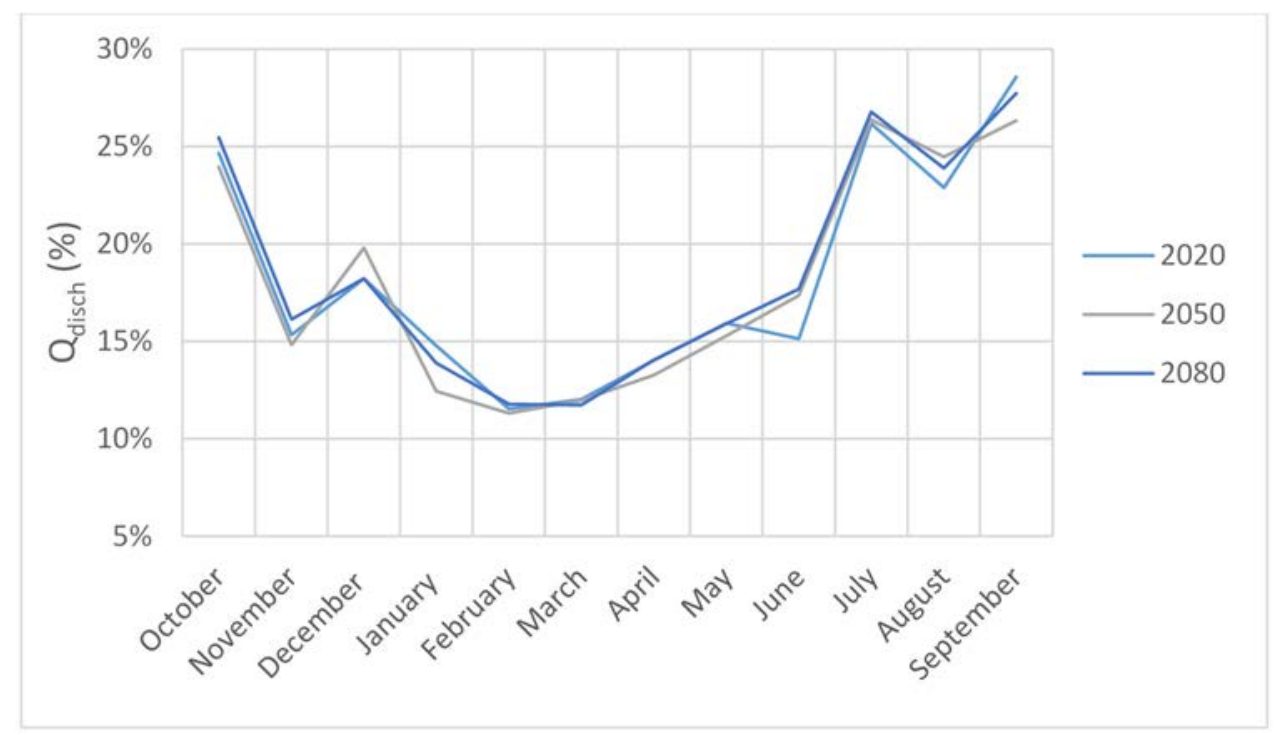

Figure 4: Annual variation of the index $\left(\mathrm{Q}_{\mathrm{disch}}\right)$ for the CIC.

Then, the annual variation was analysed by zones, and is illustrated in Fig. 5: Upper Llobregat (Fig. 5(a)); Lower Llobregat (Fig. 5(b)); Upper Ter (Fig. 5(c)); Lower Ter (Fig. 5(d)) and Coast Basins (Fig. 5(e)). Firstly, the results show an index increase between upper and lower basins of the two main rivers, Llobregat and Ter. This difference reaches values of as much as 15 points higher in the low areas than in the high areas during the same month. This situation is because it is in the lower part of the rivers, near the coast, where most of the population living in the Catalan Internal Basins is located.

The most significant case is that of the coastal basins, characterized by irregular regimes, which are aquatic ecosystems very vulnerable to both quantitative and qualitative alterations. As the results show, in this case, the average streamflows from urban discharges reach $40 \%$ of the total during the summer months. 


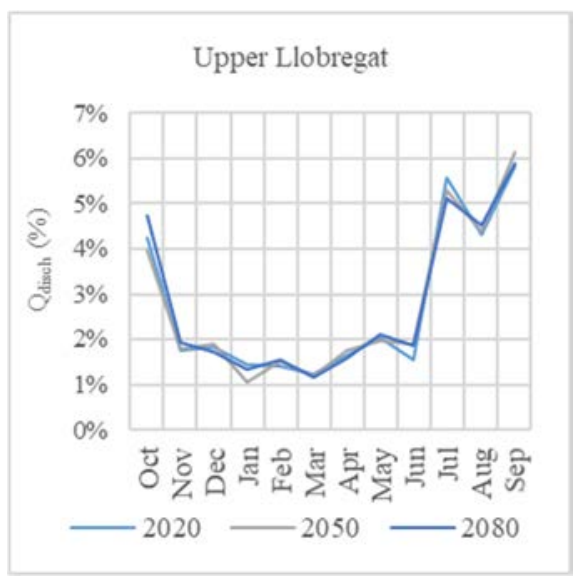

(a)

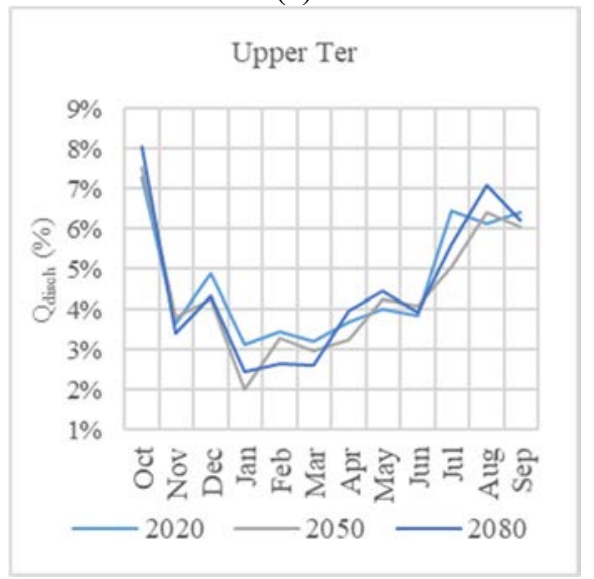

(c)

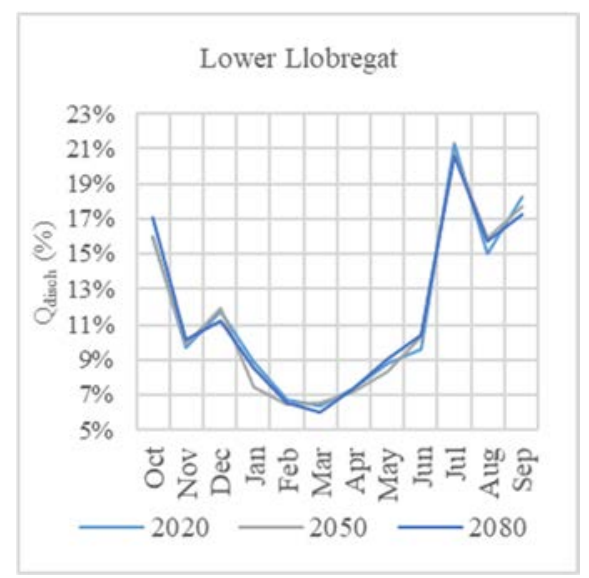

(b)

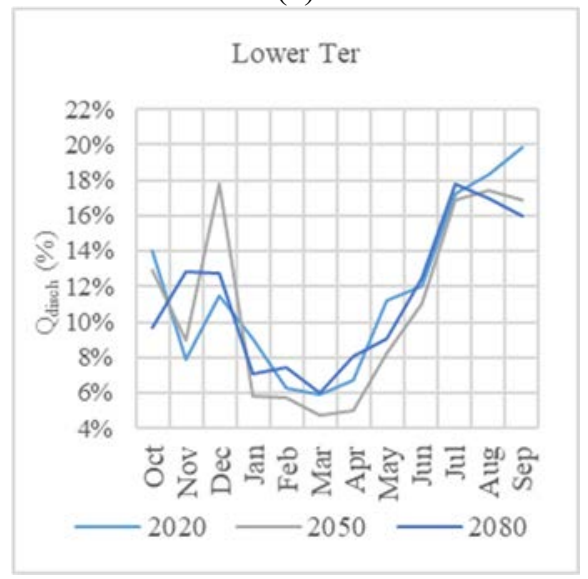

(d)

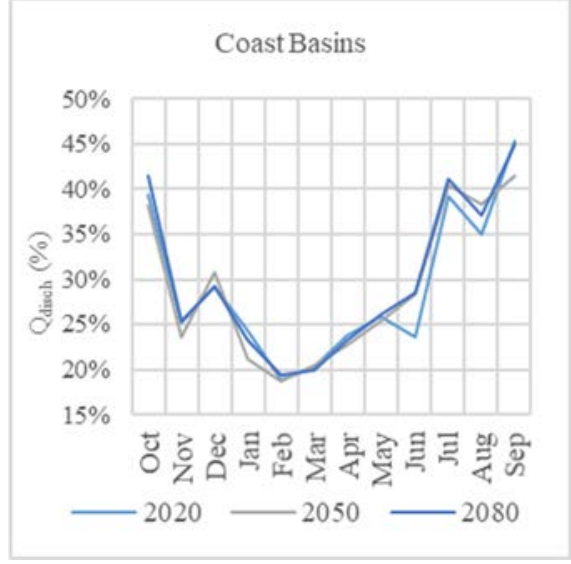

(e)

Figure 5: Annual variation of the index $\left(\mathrm{Q}_{\text {disch }}\right)$ by zone. (a) Upper Llobregat; (b) Lower Llobregat; (c) Upper Ter; (d) Lower Ter; (e) Coast Basins. 
Finally, no significant impacts have been detected among the Climate Change scenarios presented in any of the areas studied. Therefore, the results in this sense are not conclusive.

In order to identify the masses that suffer the greatest pressure, the maximum values registered during the simulated period were presented per mass of water, in map format (Fig. 6 ). The maximum value is represented because it is related to the most critical situation that each body of water can reach.

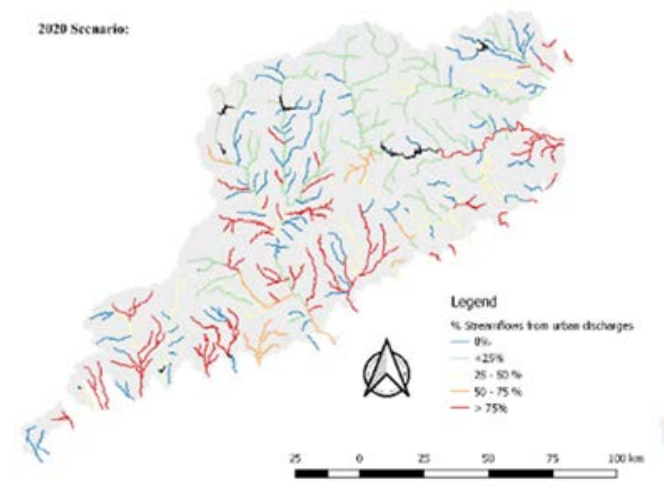

(a)

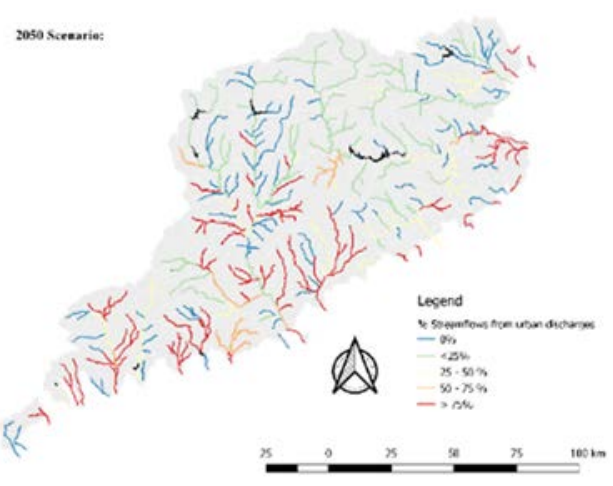

(b)

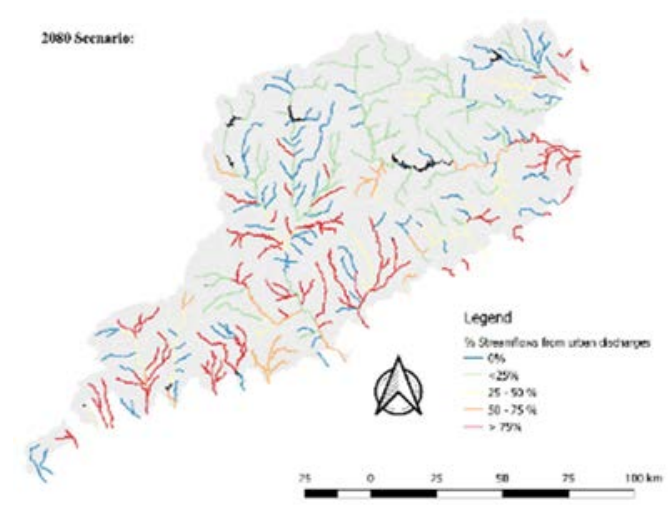

(c)

Figure 6: Maximum value of the index ( $\left.\mathrm{Q}_{\text {disch }}\right)$ during the simulated period by water body. (a) 2020 Scenario; (b) 2050 Scenario; (c) 2080 Scenario.

As in Fig. 5, a higher risk is identified in the lowlands and coastal areas where the pressure from urban discharges is higher. However, when presenting the results in map format, it is observed that most of the rivers for which the maximum value of circulating flow from WWTPs exceeds $75 \%$ are secondary rivers. These rivers are characterized by low and intermittent flows.

On the other hand, when the maps are compared with each other, there are no appreciable changes in the level of risk between the three Climate Change scenarios. Table 3 shows the number of masses classified in each group by scenario. There has been a minor improvement in the quantitative risk of urban discharges between 2020 and 2050 because, in the second 
scenario, a small increase in total inflows is expected. Finally, in the 2080 scenario, there was an increase in the number of masses that were in the range of $50-75 \%$.

Table 3: Number of water bodies by sub-class of $\mathrm{Q}_{\mathrm{disch}}$ and Climate Change scenario.

\begin{tabular}{|l|c|c|c|}
\hline No. of water bodies by \% group & $\mathbf{2 0 2 0}$ & $\mathbf{2 0 5 0}$ & $\mathbf{2 0 8 0}$ \\
\hline$>\mathbf{7 5 \%}$ & 68 & 67 & 65 \\
\hline $\mathbf{7 5 - 5 0 \%}$ & 11 & 9 & 16 \\
\hline $\mathbf{5 0 - 2 5 \%}$ & 32 & 35 & 31 \\
\hline$<\mathbf{2 5 \%}$ & 62 & 62 & 61 \\
\hline
\end{tabular}

\subsection{The percentage of demands from WWTP discharges}

The model includes 14 water extraction points for agricultural and urban demands, $520 \mathrm{Hm}^{3}$ per year. Fig. 7 presents the average percentage of the flow that comes from discharges upstream of each abstraction. It can be observed how the water bodies ES100MSPF2000420 and the ES100MSPF2000460 reach average values higher than $25 \%$.

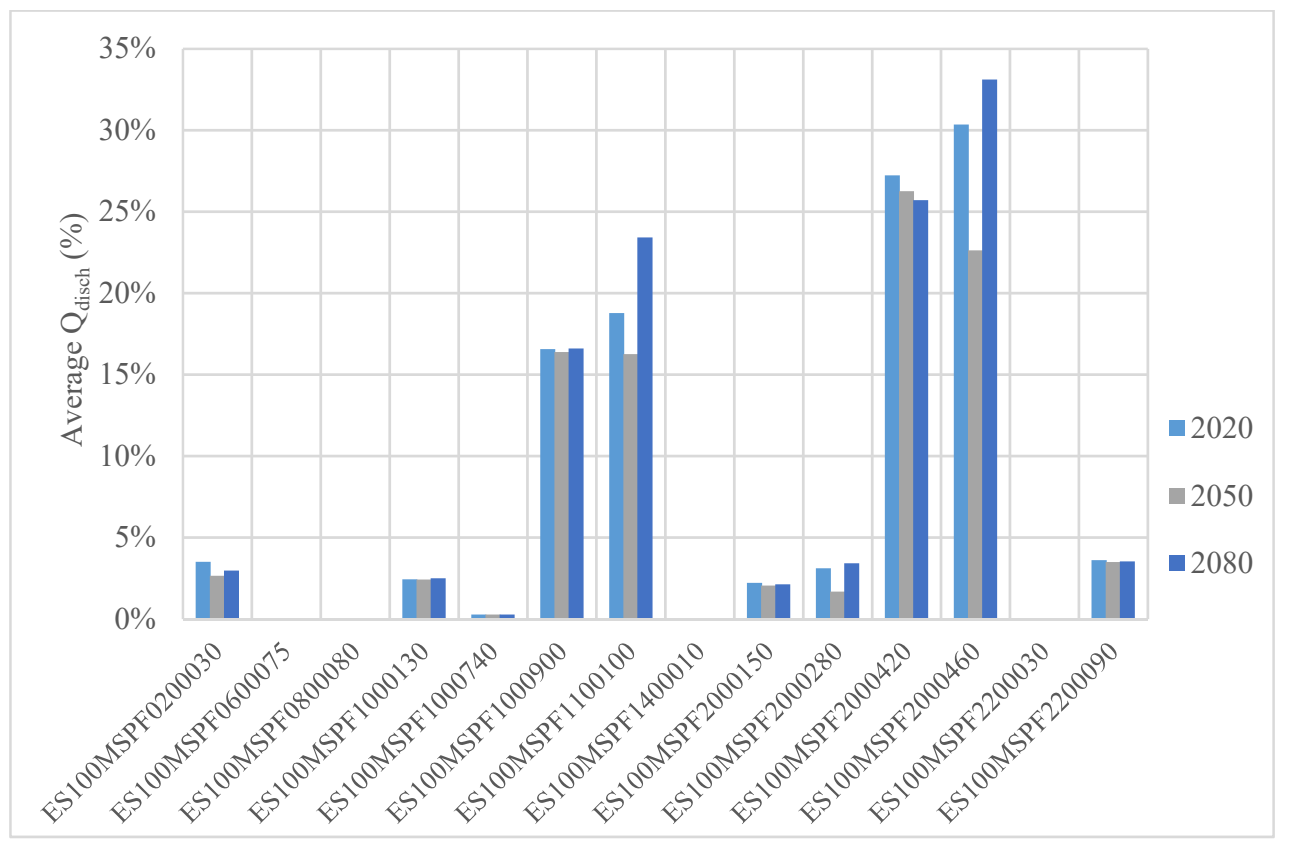

Figure 7: Average $\mathrm{Q}_{\text {disch }}$ of water bodies affected by important demands.

Finally, no clear overall trend has been identified as to how Climate Change may affect the case study.

\section{CONCLUSION}

Although the main objective of the study was to identify the effect of Climate Change on the relationship between the volumes discharged by WWTPs and natural flows, it did not identify a general trend. This is due to the fact that the SWICCA information about changes in rates 
of inflows also does not follow a clear pattern. The streamflows increase or decrease depending on the analysed area, so the total water balances are compensated.

A general trend has been observed by which the vulnerability of the analysed masses increases during the summer months. The reduction of flows and water stress situations suppose a challenge for basin managers, since the risk to which these aquatic ecosystems are subjected increases considerably. This trend increases when comparing the evolution of the indicator in each zone. Coastal areas characterized by higher population densities are subjected to greater pressure from urban discharges.

In addition, in the present study, the important role of the water that comes from urban discharges in the hydraulic balance has been demonstrated. The high anthropization level of the rivers, due necessary to take into account the role of urban discharges on the water river systems.

In summary, the $\mathrm{R}^{2} \mathrm{EA}$ model allows the opportunity for the water authorities to know the relation between urban discharges flows and total streamflows as an ecological indicator, to characterize river basins pressures, to analyse annual vulnerability variation and to simulate large periods, in order to identify the most critical situation of each of the water bodies.

\section{ACKNOWLEDGEMENTS}

The authors thank the Spanish Research Agency (MINECO) for their financial support to the ERAS project (CTM2016-77804-P, including EU-FEDER funds).

\section{REFERENCES}

[1] Pellicer-Martínez, F. \& Martínez-Paz, J.M., The Water Footprint as an indicator of environmental sustainability in water use at the river basin level. Sci. Total Environ., 571, pp. 561-574, 2016.

[2] Martínez-Paz, J., Pellicer-Martínez, F. \& Colino, J., A probabilistic approach for the socioeconomic assessment of urban river rehabilitation projects. Land Use Policy, 36, pp. 468-477, 2014.

[3] Pellicer-Martínez, F. \& Martínez-Paz, J.M., Grey water footprint assessment at the river basin level: Accounting method and case study in the Segura River Basin, Spain. Ecol. Indic., 60, pp. 1173-1183, 2016.

[4] Pophare, A.M., Lamsoge, B.R., Katpatal, Y.B. \& Nawale, V.P., Impact of overexploitation on groundwater quality: A case study from WR-2 watershed, India. J. Earth Syst. Sci., 123(7), pp. 1541-1566, 2014.

[5] Foster S. et al., Quaternary aquifer of the North China Plain: Assessing and achieving groundwater resource sustainability. Hydrogeol. J., 12(1), pp. 81-93, 2004.

[6] Sultana, M.N., Uddin, M.M., Ridoutt, B.G. \& Peters, K.J., Comparison of water use in global milk production for different typical farms. Agric. Syst., 129, pp. 9-21, 2014.

[7] Rijsberman, F.R., Water scarcity: Fact or fiction?. Agric. Water Manag., 80(1-3), Special Issue, pp. 5-22, 2006.

[8] Sandoval-Solis, S., McKinney, D.C. \& Loucks, D.P., Sustainability Index for Water Resources Planning and Management. J. Water Resour. Plan. Manag., 137(5), pp. 381390, 2010.

[9] Generalitat de Catalunya \& Agència Catalana de l'Aigua, Pla de gestió del districte de conca fluvial de Catalunya (2016-2021). Government agreement issued by Department of Territory and Sustainability, 2017. 